\title{
Synthesis of pure potassium pentaborate (KB5) from potassium dihydrogen phosphate (KH2PO4) and colemanite
}

Özlem Karagöz ( $\square$ ozlemkaragoz@atauni.edu.tr)

Atatürk University

Soner Kuşlu

Atatürk University

\section{Research Article}

Keywords: Potassium dihydrogen phosphate, Potassium pentaborate, Colemanite, Crystallization, Slow evaporation solution method

Posted Date: February 15th, 2021

DOl: https://doi.org/10.21203/rs.3.rs-226838/v1

License: (c) (i) This work is licensed under a Creative Commons Attribution 4.0 International License.

Read Full License

Version of Record: A version of this preprint was published at Chemical Papers on July 11th, 2021. See the published version at https://doi.org/10.1007/s11696-021-01771-z. 


\title{
Synthesis of pure potassium pentaborate $\left(\mathrm{KB}_{5}\right)$ from potassium dihydrogen phosphate $\left(\mathrm{KH}_{2} \mathrm{PO}_{4}\right)$ and colemanite
}

\author{
Özlem Karagöz ${ }^{\mathrm{a}}$, , Soner Kuşlu ${ }^{\mathrm{b}}$ \\ ${ }^{a, b}$ Department of Chemical Engineering, Atatürk University, Erzurum, Turkey \\ * Corresponding author.E-mail address: ozlemkaragoz@atauni.edu.tr (Ö. Karagöz)
}

\begin{abstract}
In this study, after specifying theoretical reaction conditions required for chemical reaction, potassium pentaborate $\left(K B_{5}\right)$ was synthesized from the potassium dihydrogen phosphate $\left(\mathrm{KH}_{2} \mathrm{PO}_{4}\right)$ solution and the raw colemanite $\left(\mathrm{Ca}_{2} \mathrm{~B}_{6} \mathrm{O}_{11} \cdot 5 \mathrm{H}_{2} \mathrm{O}\right)$ ore. The slow evaporation solution method was used at $25{ }^{\circ} \mathrm{C}$. The effect of time (6-18 hours) on crystallization was studied. Synthesized minerals were characterized by X-ray diffraction (XRD), Fourier transform infrared (FT-IR), RAMAN spectroscopies, and scanning electron microscopy (SEM). The results according to the XRD, FT-IR, RAMAN, and SEM analyses proved that the synthesized product was the potassium pentaborate $\left(\mathrm{KB}_{5} \mathrm{O}_{8} .4 \mathrm{H}_{2} \mathrm{O}\right)$ mineral having the ICSD: 96-026-1927 pdf code. As a result, the cost was reduced by using raw boron ore, colemanite and $K B_{5}$ could be obtained in a shorter time and at a lower temperature.
\end{abstract}

Keywords: Potassium dihydrogen phosphate, Potassium pentaborate, Colemanite, Crystallization, Slow evaporation solution method 


\section{Introduction}

In recent years, there has been an increasing demand for borates family for technological applications. Inorganic borates exist in numberless structural types. Among them, potassium penta borate single crystals are the significant compounds that can be used in the industry. Containing approximately $72 \%$ of the world's boron reserves, Turkey is the country that has the largest boron deposits. Boron element, which is never found free, only forms the complex borate structures as a result of the combination of boron oxide $\left(\mathrm{B}_{2} \mathrm{O}_{3}\right)$ with the oxides of other elements [1]. Borate compounds can generally be grouped into different sub classes such as calcium borates, calcium-sodium borates, sodium borates, and magnesium borates [2]. The most important of these and the most preferred in the industry are respectively colemanite $\left(\mathrm{Ca}_{2} \mathrm{~B}_{6} \mathrm{O}_{11} \cdot 5 \mathrm{H}_{2} \mathrm{O}\right)$, tincal $\left(\mathrm{Na}_{2} \mathrm{~B}_{4} \mathrm{O}_{7} \cdot 10 \mathrm{H}_{2} \mathrm{O}\right)$ and ulexite $\left(\mathrm{NaCaB}_{5} \mathrm{O}_{9} \cdot 8 \mathrm{H}_{2} \mathrm{O}\right)$ [3]. However, many synthetic borate compounds have been preferred and used in the industry apart from those found in nature. One of them, potassium pentaborate tetrahydrate $\left(\mathrm{KB}_{5} \mathrm{O}_{8} \cdot 4 \mathrm{H}_{2} \mathrm{O}\right)$, which contains 4 moles of structural water per mole of crystalline, is one of the important borate compounds and generally shown in the literature with the formula " $K B_{5}$ " rather than potassium pentaborate tetrahydrate [4]. $K B_{5}$ crystals are uncolored, chemically stable and optically biaxial compounds. Potassium pentaborate, can be used in welding, insulation, lubricating oil additives, metal refining, cement, textile, fiberglass, and non-linear materials. Last researches on effective nonlinear optical (NLO) materials show that $K B_{5}$ crystals are superior to other mostly used NLO materials. That is why potassium pentaborate, is successfully used to convert significant laser radiation and inorganic NLO crystal into UV and vacuum UV wavelength region [5-8].

$K B_{5}$ crystals can usually be obtained by reacting boric acid and $\mathrm{KOH}$ in an aqueous medium by keeping the mole ratio of $\mathrm{B}_{2} \mathrm{O}_{3} / \mathrm{K}_{2} \mathrm{O}$ around 5 [9]. The chemical equation for the synthesis of $K B_{5}$ crystal using the traditional method is as given in equation 1.

$$
\mathrm{KOH}(a q)+5 \mathrm{H}_{3} \mathrm{BO}_{3}(a q) \rightarrow \mathrm{KB}_{5} \mathrm{O}_{8} .4 \mathrm{H}_{2} \mathrm{O}(a q)+4 \mathrm{H}_{2} \mathrm{O}(s)
$$


Owing to the chemical and optical significance of potassium borates, many investigators show an interest in their synthesis and application in different fields. There are some studies in the literature where potassium pentaborate is produced by changing the potassium and boron sources. The literature summary of these studies is given below.

Rajasekar et al. [10] have achieved to obtain $\mathrm{KB}_{5}$ by dissolving $\mathrm{K}_{2} \mathrm{CO}_{3}$ and $\mathrm{H}_{3} \mathrm{BO}_{3}$ in suitable proportions in double-distilled water. Growth conditions and surface morphology of the crystals of pure and magnesium, calcium, barium, and copper doped $K B_{5}$ have been optimized and magnified crystals have been verified by XRD. Prabha et al. [11] used the lowtemperature slow solvent evaporation method and characterized pure and 1, 10 phenanthroline doped $K B_{5}$ and determined their potential as a non-linear optical material. Yıldırım et al. [12] aimed to produce potassium borate compounds by the hydrothermal method. In the study where the reaction temperature and reaction time were determined as $80^{\circ} \mathrm{C}$ and 1 hour, $K B_{5}$ was produced by mixing different moles of $\mathrm{KNO}_{3}$, as the potassium source, $\mathrm{NaOH}$ as the hydroxide ion source and $\mathrm{H}_{3} \mathrm{BO}_{3}$ as the boron source. Kıpçak et al. [5] used $\mathrm{KCl}$ as a potassium source, $\mathrm{NaOH}$ as a hydroxide ion source, $\mathrm{B}_{2} \mathrm{O}_{3}$ as a boron source and reacted to them in different mole ratios. As a result of the experiment, they achieved optimum efficiency in a mole ratio of 1:1:7 (KCl: $\mathrm{NaOH}: \mathrm{B}_{2} \mathrm{O}_{3}$ ). Vigneshwaran et al. [13] reacted $\mathrm{K}_{2} \mathrm{CO}_{3}$ and $\mathrm{H}_{3} \mathrm{BO}_{3}$ in the ratio of 1:10 moles and synthesized $K B_{5}$ crystals. The obtained crystals were kept in a $32{ }^{\circ} \mathrm{C}$ constant temperature bath for 50-60 days using pure water. Thus, the crystals were grown by a slow evaporation solution growth technique. Asensio et al. [14] managed to obtain the $K B_{5}$ crystal in $84.88 \%$ and $95.11 \%$ yield using $\mathrm{K}_{2} \mathrm{CO}_{3}, \mathrm{H}_{3} \mathrm{BO}_{3}$ and $\mathrm{B}_{2} \mathrm{O}_{3}$. The researchers, who found that the crystal they obtained lost their crystal water at $500-450{ }^{\circ} \mathrm{C}$, also examined the crystalline thermal dehydration kinetics and characterized them by using thermal gravimetry and differential thermal analysis. Derun, [15] used potassium chloride $(\mathrm{KCl})$ as a source of potassium, and tincalconite, borax $\left(\mathrm{Na}_{2} \mathrm{~B}_{4} \mathrm{O}_{7} \cdot 10 \mathrm{H}_{2} \mathrm{O}\right)$, boric acid $\left(\mathrm{H}_{3} \mathrm{BO}_{3}\right)$ and boron oxide $\left(\mathrm{B}_{2} \mathrm{O}_{3}\right)$ as a source of boron.

$K B_{5}$ was synthesized at temperatures above $200{ }^{\circ} \mathrm{C}$ and more than 1 week using the conventional hydrothermal method in the literature. In these studies, researchers generally preferred pure boric acid as a boron source and $\mathrm{KOH}, \mathrm{KNO}_{3}, \mathrm{~K}_{2} \mathrm{CO}_{3}$ as a source of potassium $[13,16-21]$. But boric acid is also a product and is more expensive than unprocessed raw ore. 
In this study, different potassium source $\left(\mathrm{KH}_{2} \mathrm{PO}_{4}\right.$ solution) and different boron source (raw colemanite ore) were used for the first time in literature in order to obtain low cost $K_{5}$ single crystal under the conditions of low temperature and short time. The optimum dissolution condition was taken from the our previous studies $[22,23]$. Various slow evaporation times were tried to obtain the best $K B_{5}$ single crystal.

\section{Materials and Methods}

The boron source of colemanite was obtained from Emet-Mine in Kütahya, Turkey. The potassium source of potassium dihydrogen phosphate (Merck reagent of 99.9\% purity) was used in the experiments. The colemanite samples were crushed, ground, and then sieved by using ASTM standard sieves to obtain $165 \mu \mathrm{m}$ average size fraction. The chemical composition of the ore was determined by volumetric and gravimetric methods. The chemical analyses of colemanite ore are given in Table 1.

Table 1. Chemical analysis of colemanite ore

\begin{tabular}{lllll}
\hline Component & $\mathbf{B}_{2} \mathbf{O}_{3}$ & $\mathbf{C a O}$ & $\mathbf{H}_{\mathbf{2}} \mathbf{O}$ & $\mathbf{S i O}_{\mathbf{2}}$ and others \\
\hline$\%$ & 44,20 & 26,75 & 22,20 & 6,40 \\
\hline
\end{tabular}

XRD analyzes were performed. by a PANalytical Empyrean X-ray diffractometer (XRD) by using $\mathrm{Cu}-\mathrm{K} \alpha$ radiation. Operating parameters of the device were $2 \theta$ range of $10^{\circ}-90^{\circ}, 45 \mathrm{kV}$ and $40 \mathrm{~mA}(\lambda=1.53 \mathrm{~nm})$. X-ray diffraction was used in the original sample. X-ray diffraction of colemanite ore can be seen in Fig. 1. Scanning Electron Microscope with Sistem Zeiss brand and Sigma 300 model was used to take SEM images. Fourier Transform Infrared Spectroscopy (FT-IR) with Bruker VERTEX 70w was used for FT-IR analyzes and WTech alpha $300 \mathrm{R}$ brand Raman spectroscopy was used for RAMAN analysis. The characteristic peaks of borate compounds were found in the range of $500-1500 \mathrm{~cm}^{-1}$ from the researches in the literature. For this reason, 400-1800 $\mathrm{cm}^{-1}$ spectral range for FT-IR spectroscopy and RAMAN Spectroscopy was studied $[5,14]$. 


\section{Experimental Procedure}

The Kinetic mechanism and optimum dissolution conditions of colemanite in $\mathrm{KH}_{2} \mathrm{PO}_{4}$ solution were determined in our previous reports [22, 23]. These optimum conditions were given respectively as the following: reaction temperature; $333 \mathrm{~K}$, grain size; $165 \mu \mathrm{m}$, solid/liquid rate; $0,02 \mathrm{~g} / \mathrm{mL}, \mathrm{KH}_{2} \mathrm{PO}_{4}$ concentration; $2,0 \mathrm{M}$, and time; 60 minute. Firstly the $200 \mathrm{~mL}$ of $\mathrm{KH}_{2} \mathrm{PO}_{4}$ solution and colemanite was dissolved in deionized water at ambient temperature by using a magnetic stirrer for about $300 \mathrm{rpm} .98 \%$ of $\mathrm{B}_{2} \mathrm{O}_{3}$ was dissolved as a result of the verification experiment carried out under the mentioned conditions. The experimental setup was shown in Fig. 2.

At the second stage, the solution of the verification experiment was used to synthesize potassium pentaborate tetrahydrate $\left(\mathrm{KB}_{5} \mathrm{O}_{8} .4 \mathrm{H}_{2} \mathrm{O}\right)$ product. This solution obtained under optimum conditions was crystallized at different times at $25^{\circ} \mathrm{C}$. In this study, the chemical equations (2-3) governing the reaction were given as follows,

$2 \mathrm{CaO} .3 \mathrm{~B}_{2} \mathrm{O}_{3} .5 \mathrm{H}_{2} \mathrm{O}_{(\mathrm{k})}+4 \mathrm{KH}_{2} \mathrm{PO}_{4(\mathrm{k})}+6 \mathrm{H}_{2} \mathrm{O}_{(\mathrm{s})} \rightarrow 2\left[\mathrm{CaHPO}_{4} \cdot 2 \mathrm{H}_{2} \mathrm{O}\right]_{(k)}+6 \mathrm{H}_{3} \mathrm{BO}_{3(\mathrm{aq})}+$ $2 \mathrm{~K}_{2} \mathrm{HPO}_{4(a q)}$

$\frac{1}{2} \mathrm{~K}_{2} \mathrm{HPO}_{4(a q)}+5 \mathrm{H}_{3} \mathrm{BO}_{3}(a q) \rightarrow K\left(\mathrm{H}_{4} B_{5} \mathrm{O}_{10}\right) \cdot 2 \mathrm{H}_{2} \mathrm{O}(a q)+\frac{7}{2} \mathrm{H}_{2} \mathrm{O}(l)+\frac{1}{2} \mathrm{HPO}_{3}(a q)$

As a result of the dissolution, $\mathrm{K}\left(\mathrm{H}_{4} \mathrm{~B}_{5} \mathrm{O}_{10}\right) \cdot 2 \mathrm{H}_{2} \mathrm{O}(\mathrm{aq})$ could be obtained in an aqueous medium as in equation (3). Hot filtering was done at $333 \mathrm{~K}$ with Whatman filter papers to remove impurities. The filtered solution was covered with porous papers and kept in a dust-free environment for crystallization. The effect of time on crystallization was examined. The solution containing the remaining $K B_{5}$ was crystallized at $25^{\circ} \mathrm{C}$ using the slow evaporation solution technique for 6,12 , and 18 hours. 


\section{Result and Discussion}

The solutions obtained three times by dissolving colemanite in the $\mathrm{KH}_{2} \mathrm{PO}_{4}$ solutions were crystallized at 6,12 , and 18 hours to ensure the formation of $K B_{5}$ single crystals which were named as $K B_{5}-6$ hour, $K B_{5}-12$ hour, $K B_{5}-18$ hour. Powder XRD pattern of $K B_{5}$ crystals obtained at different times can be seen in Fig. 3. When XRD patterns are examined thoroughly, characteristic XRD peaks of potassium borates cannot be seen until the time reached 18 hour. According to XRD results, the produced inorganic borate minerals are potassium pentaborate $\left(\mathrm{KB}_{5} \mathrm{O}_{8} \cdot 4 \mathrm{H}_{2} \mathrm{O}\right)$ having the ICSD: $96-026-1927$ pdf code at 18 hour. The powder XRD pattern of the $K B_{5}$ crystal obtained in 18 hour can be seen clearly and in detail in Fig. 4.

SEM images obtained on the product crystallized by slow evaporation method for 18 hour were taken from different parts of the products. SEM images of $K B_{5}-18$ hour product at different magnifications a) $200 \mathrm{~nm}$, b) $1 \mu \mathrm{m} \mathrm{c}) 2 \mu \mathrm{m}$ and d) $10 \mu \mathrm{m}$ were given in Fig. 5. As can be seen from the Fig. 5. Potassium borate particles are in the form of homogeneous, angularly arranged, and polyhedral aggregates. The images in the study of Asensio et al. Confirm this sequence [14].

FT-IR spectrum of potassium borates synthesized for $K B_{5}-18$-hour product is given in Fig. 6. According Fig. 6 the IR peak at around $1360 \mathrm{~cm}^{-1}$ are assigned to asymmetric stretching of $\mathrm{B}-\mathrm{O}$. The peak appears at $1250 \mathrm{~cm}^{-1}$ has been attributed to the bending vibration of the $\mathrm{B}-\mathrm{O}$ bond. The peaks wavenumber of at $922 \mathrm{~cm}^{-1}$ belong to the ring stretching of $\mathrm{B}-\mathrm{O}$. The O-B-O terminal bending appears at $592 \mathrm{~cm}^{-1}$. In-plane O-B-O ring bending of $\mathrm{B}-\mathrm{O}$ is observed at 510 $\mathrm{cm}^{-1}$. Raman spectrum of $K B_{5}-18$ hour is given in Fig. 7. FT-IR and Raman spectra of the products appear to give typical potassium borate peaks in both the infrared and visible regions [24]. 


\section{Conclusions}

- The raw boron ore colemanite was dissolved in $\mathrm{KH}_{2} \mathrm{PO}_{4}$ solution under optimum dissolution conditions.

- $\mathrm{K}_{2} \mathrm{HPO}_{4(a q)}$ and $\mathrm{H}_{3} \mathrm{BO}_{3(a q)}$, which were dissolved in the solution, were crystallized at different times $(6,12$ and 18 hour) by slow evaporation solution method and a single crystal $K B_{5}$ was obtained.

- Prepared samples were identified using the technique of X-ray diffraction (XRD). XRD analysis results of $K B_{5}$ crystals obtained at different times showed that the best peaks were obtained with 18 hours. The same sample was characterized using the spectroscopic methods of Fourier transform infrared (FT-IR) and Raman. Morphological properties were investigated with a scanning electron microscope (SEM).

- The analyses were made and the taken results according to the XRD, FT-IR, RAMAN, and SEM images confirmed that the synthesized product was the potassium pentaborate $\left(\mathrm{KB}_{5} \mathrm{O}_{8} .4 \mathrm{H}_{2} \mathrm{O}\right)$ mineral having the ICSD: 96-026-1927 pdf code.

- The cost was reduced by using raw boron ore, and $K B_{5}$ could be obtained in a shorter time and at a lower temperature.

\section{Declaration of Competing Interest}

No potential conflict of interest was reported by the authors. 


\section{Referances}

[1] L.D. Pye, V.D. Fréchette, N.J. Kreidl, Borate glasses: structure, properties, applications, Springer Science \& Business Media2012.

[2] Ö. Küçük, M.M. Kocakerim, A. Yartasi, M. Çopur, Dissolution of kestelek's colemanite containing clay minerals in water saturated with sulfur dioxide, Industrial \& Engineering Chemistry Research 41(12) (2002) 2853-2857.

[3] Ö. Karagöz, M. Çopur, M.M. Kocakerim, Kinetic analysis of retention of SO2 using waste ulexite ore in an aqueous medium, Journal of hazardous materials 353 (2018) 214-226.

[4] G. Yang, Z. Li, Y. Zhang, Dehydration of tetrahydrate potassium pentaborate in fluidized bed, Chemical Engineering and Processing: Process Intensification 44(11) (2005) 1216-1220.

[5] S. Kıpçak, M. Günal, I. Sibel, M. Yıldırım, M. Piskin, E. Derun, Determination Optimum B2O3, $\mathrm{KCl}$ and $\mathrm{NaOH}$ Molar Ratios in the Synthesis of Potassium Borates, Celal Bayar Üniversitesi Fen Bilimleri Dergisi 11(3) (2015).

[6] K. Kamatchi, P. Umarani, T. Radhakrishnan, C.R. Raja, Investigation on organicinorganic hybrid NLO crystal L-Valine Potassium Penta Borate octa hydrate (LVPPB) for NLO applications, Optik 172 (2018) 674-679.

[7] D. Xue, K. Betzler, H. Hesse, D. Lammers, Nonlinear optical properties of borate crystals, Solid State Communications 114(1) (2000) 21-25.

[8] R.A. Kumar, M. Arivanandhan, Y. Hayakawa, Recent advances in rare earth-based borate single crystals: Potential materials for nonlinear optical and laser applications, Progress in crystal growth and characterization of materials 59(3) (2013) 113-132.

[9] H. Gürbüz, G. Badem, A. Bulutçu, Determination of crystal growth kinetics of potassium pentaborate in a fluidized bed crystallizer, Journal of crystal growth 283(12) (2005) 222-229.

[10] S.A. Rajasekar, K. Thamizharasan, A.J.A. Pragasam, J.P. Julius, P. Sagayaraj, Growth and characterization of pure and doped potassium pentaborate (KB5) single crystals, Journal of crystal growth 247(1-2) (2003) 199-206.

[11] K. Prabha, M.R. Babu, P. Sagayaraj, Growth and characterization of pure and 1, 10 phenanthraline doped potassium penta borate (KB5) single crystals, IOP Conference Series: Materials Science and Engineering, IOP Publishing, 2013, p. 012006.

[12] M. Yildirim, A. Kipcak, F. Senberber, M. Asensio, E. Derun, S. Piskin, The Determination of the Potassium Nitrate, Sodium Hydroxide and Boric Acid Molar Ratio in the Synthesis of Potassium Borates via Hydrothermal Method, World Academy of Science, Engineering and Technology, International Journal of Chemical, Molecular, Nuclear, Materials and Metallurgical Engineering 9(5) (2015) 605-608.

[13] A. Vigneshwaran, A.A. Joseph, C.R. Raja, A study on the properties of potassium pentaborate crystals, Optik-International Journal for Light and Electron Optics 127(13) (2016) 5365-5369. 
[14] M.O. Asensio, M. Yildirim, F.T. Senberber, A.S. Kipcak, E.M. Derun, Thermal dehydration kinetics and characterization of synthesized potassium borates, Research on Chemical Intermediates 42(5) (2016) 4859-4878.

[15] E.M. DERUN, Sodyum Boratlardan Potasyum Borat Sentezi: Reaksiyon Koşullarının Optimizasyonu, Journal of Science and Engineering 20(59) (2018).

[16] C.B. Job, Growth and characterization of sodium penta borate crystal, Int. J. Chem. Technol. Res. 8 (2015) 898-904.

[17] R. Arivuselvi, P.R. Babu, Investigation of inorganic nonlinear optical potassium penta borate tetra hydrate (PPBTH) single crystals grown by slow evaporation method, Physica B: Condensed Matter 533 (2018) 17-21.

[18] M. Lakshmipriya, D.R. Babu, R.E. Vizhi, Nucleation kinetics, growth, and optical properties of Potassium pentaborate single crystals, Physica B: Condensed Matter 430 (2013) 6-9.

[19] Z. Apagyi, L.J. Csetenyi, Phase equilibrium study in the CaO-K2O-B2O3-H2O system at $25^{\circ} \mathrm{C}$, Cement and concrete Research 31(7) (2001) 1087-1091.

[20] V. Joseph, S. Gunasekaran, V. Santhanam, Photoconductivity and dielectric studies of potassium pentaborate crystal (KB5), Bulletin of Materials Science 26(4) (2003) 383-386.

[21] F.T. ŞENBERBER, The Effect of The Reaction Conditions on The Synthesis and Characterization of Potassium Borate from Potassium Chloride, Akademik Platform Mühendislik ve Fen Bilimleri Dergisi 6(3) 92-96.

[22] O. Karagoz, S. Kuslu, OPTIMIZATION OF DISSOLUTION OF COLEMANITE ORE IN POTASSIUM DIHYDROGEN PHOSPHATE SOLUTION (KH2PO4), PressAcademia Procedia 5(1) 402-409.

[23] Ö. Karagöz, S. Kuşlu, Dissolution kinetics of colemanite in potassium dihydrogen phosphate solution (KH2PO4), International Journal of Hydrogen Energy 42(36) (2017) 23250-23259.

[24] L. Jun, X. Shuping, G. Shiyang, FT-IR and Raman spectroscopic study of hydrated borates, Spectrochimica Acta Part A: Molecular and Biomolecular Spectroscopy 51(4) (1995) 519-532. 
Figures

\section{Colemanite}

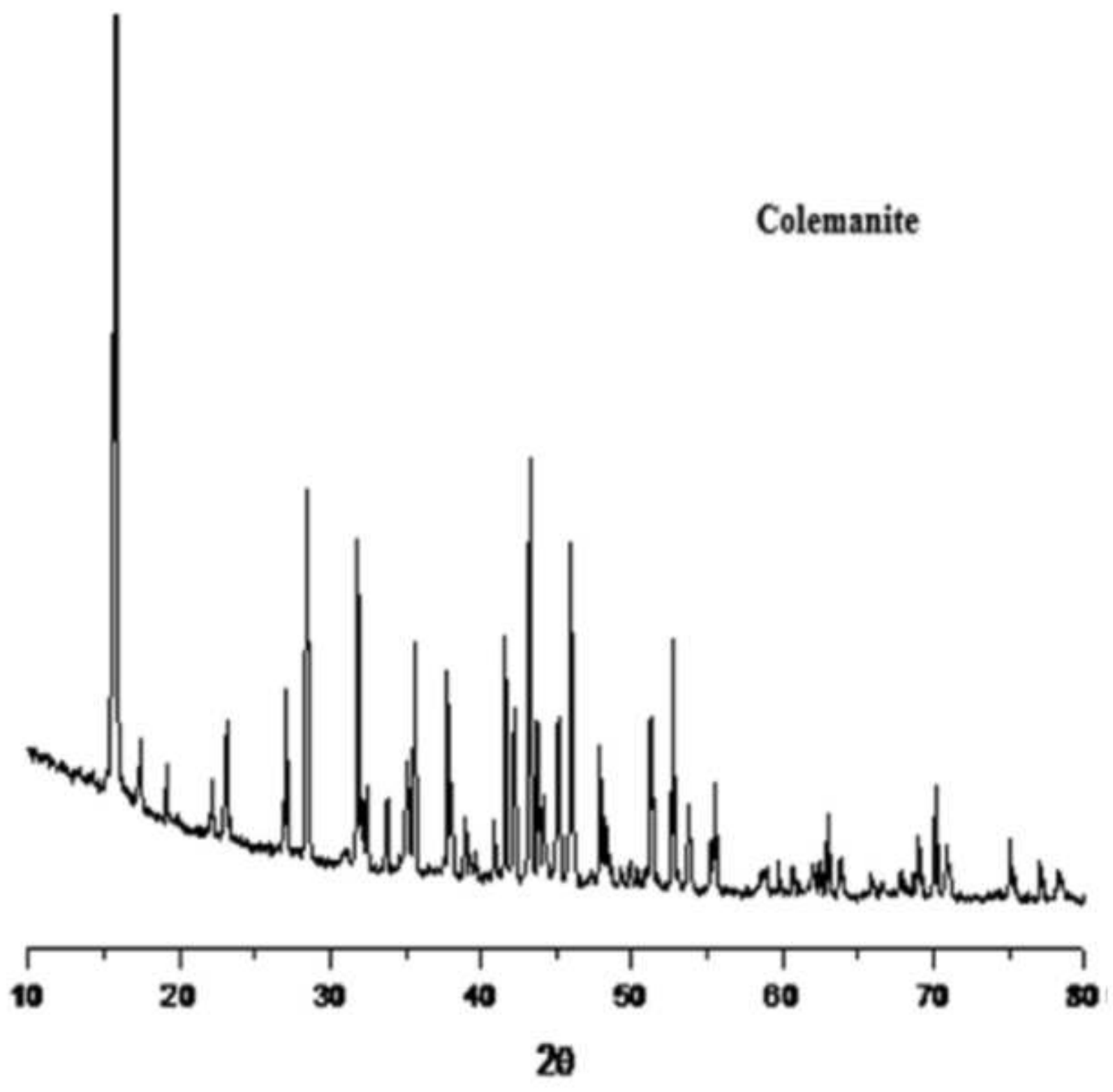

Figure 1

X-ray diffraction of colemanite ore. 


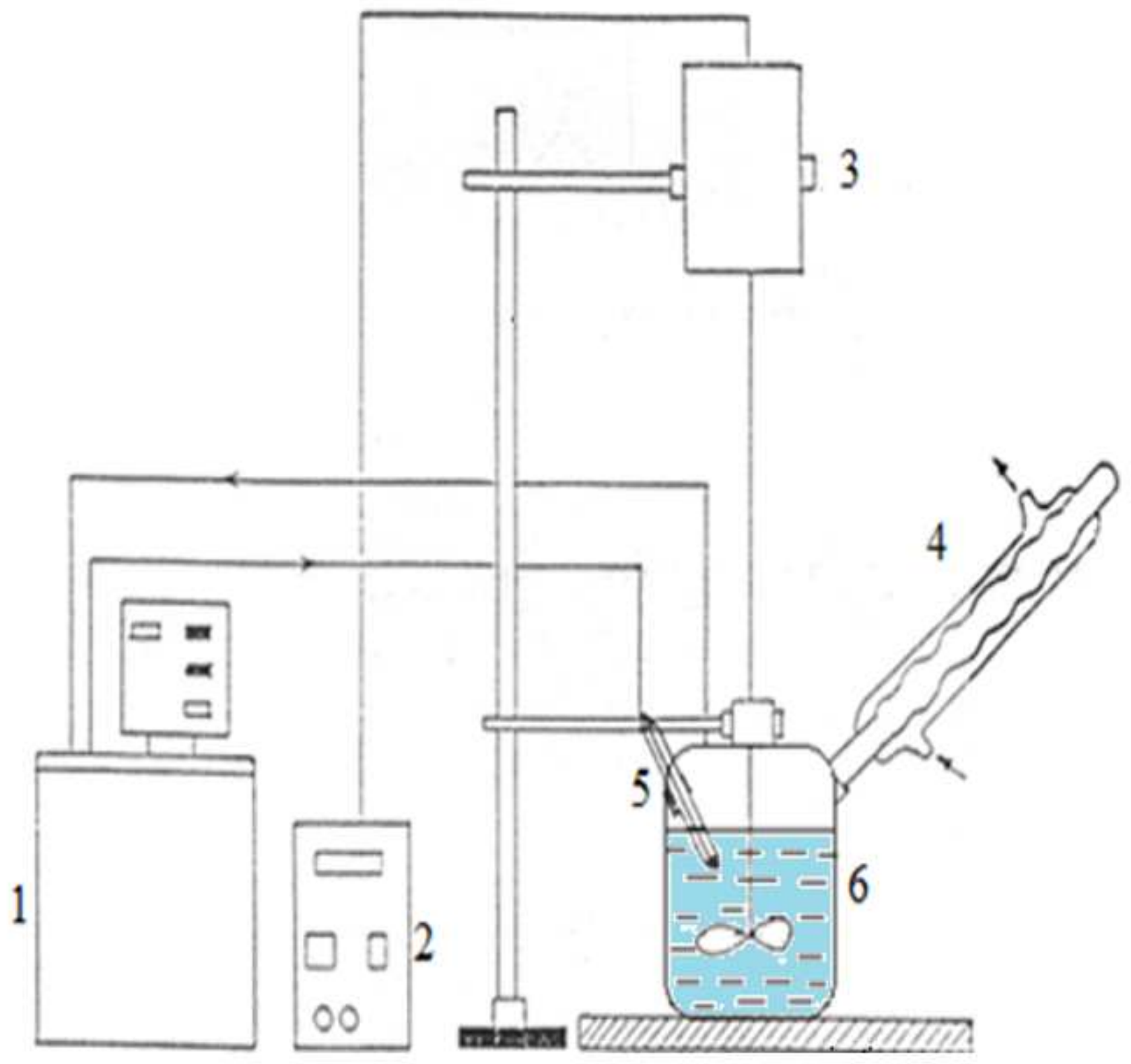

Figure 2

The experimental setup 


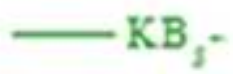

6 hour
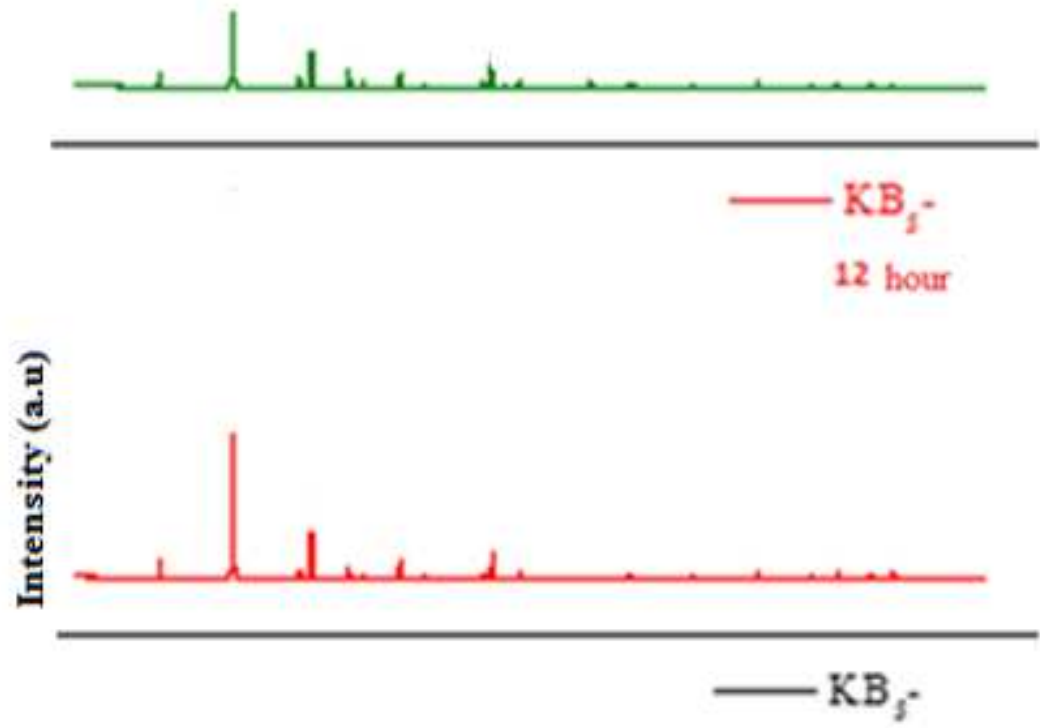

18 hour

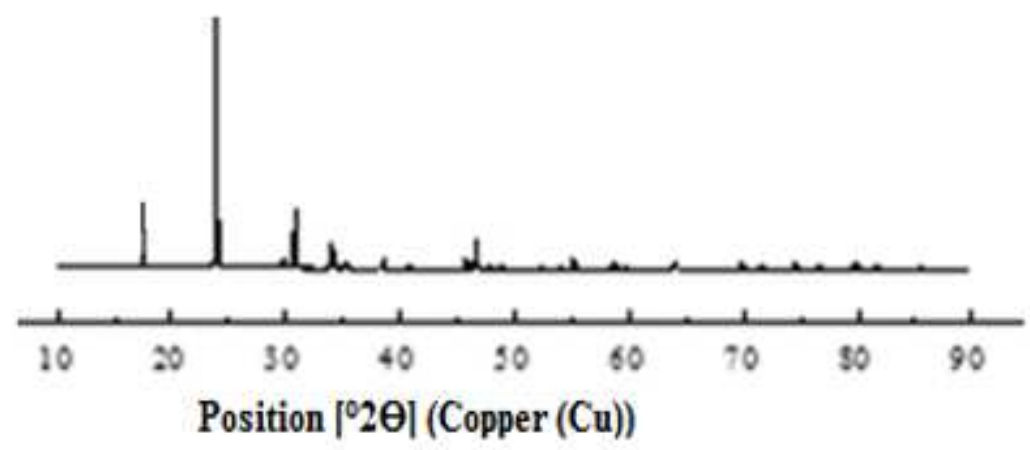

Figure 3

Powder XRD pattern of KB5 crystals obtained at different times. 


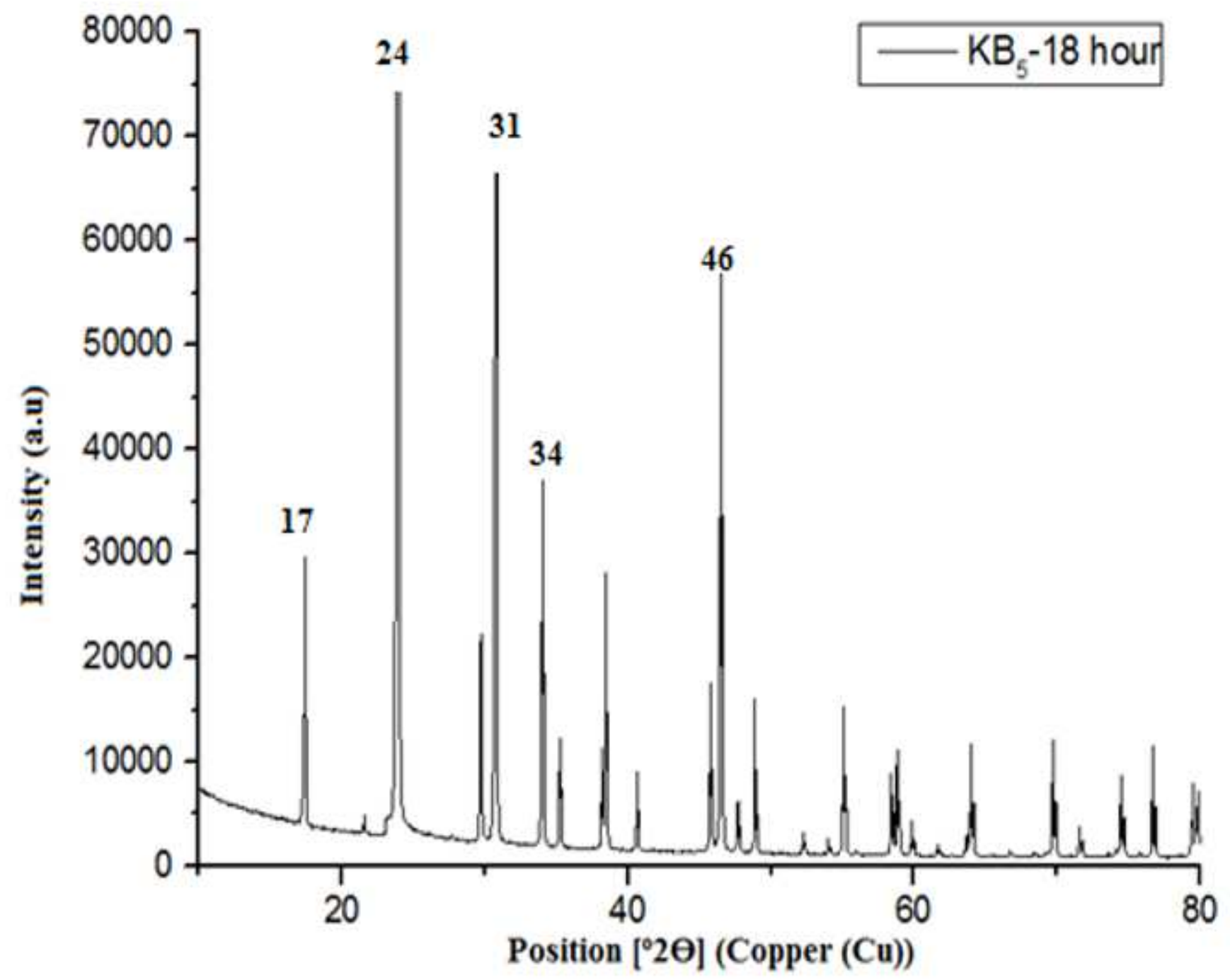

Figure 4

Powder XRD pattern of KB5 crystal obtained at 18 hour 


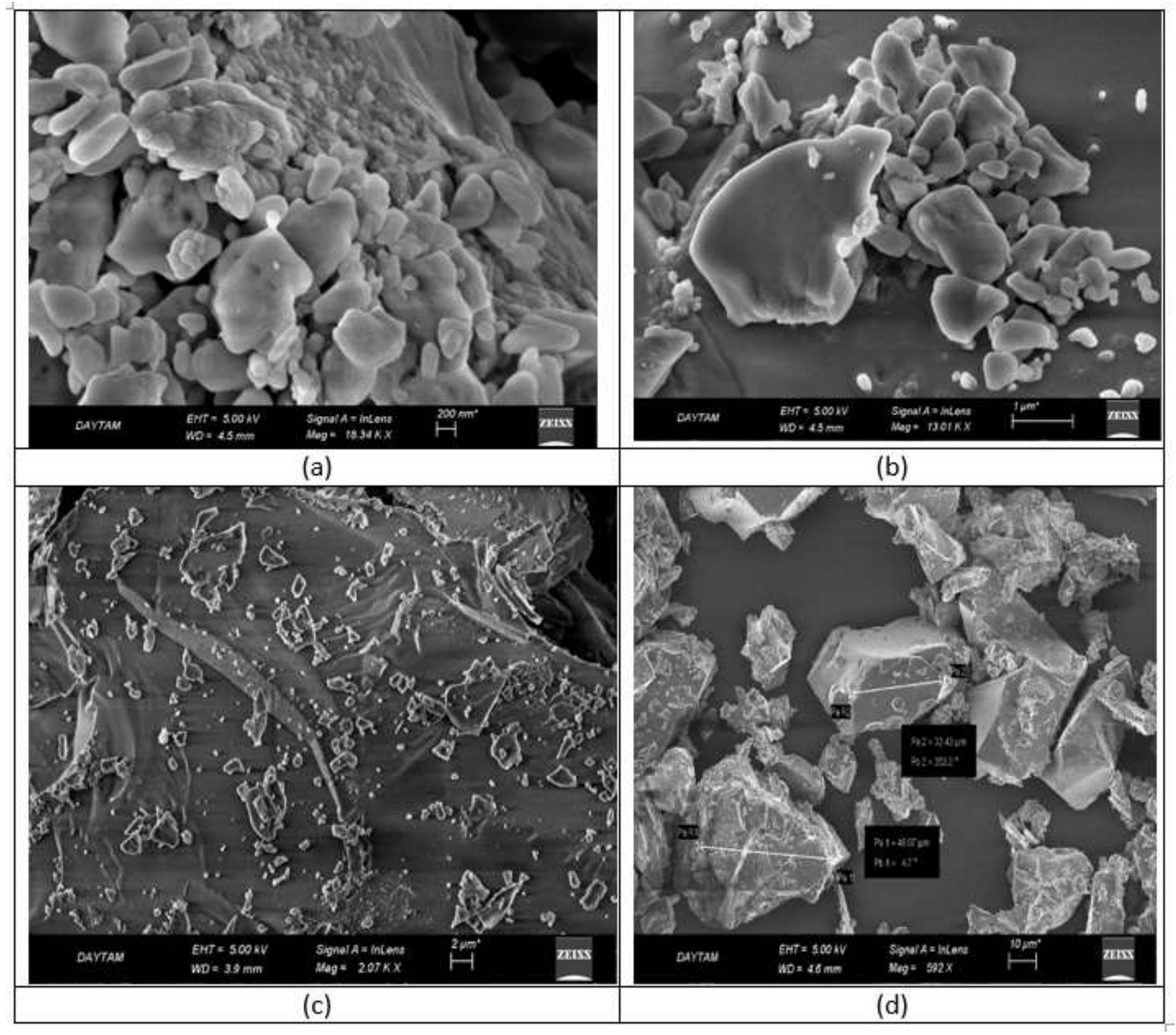

Figure 5

SEM images of KB5-18-hour product a) $200 \mathrm{~nm}$, b) $1 \mu \mathrm{m}$ c) $2 \mu \mathrm{m}$ and d) $10 \mu \mathrm{m}$ size 


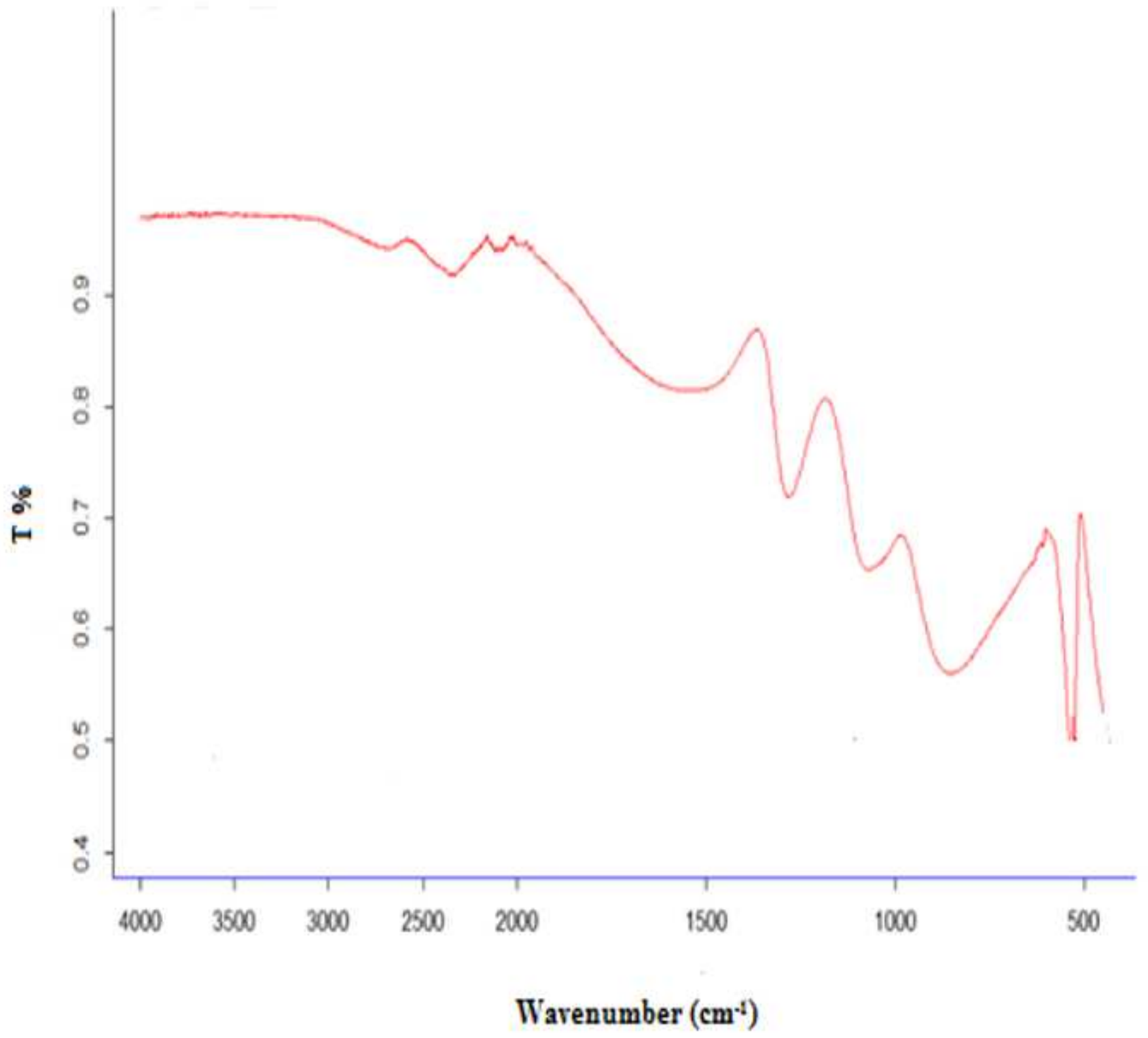

Figure 6

FT-IR spectra of potassium borates synthesized for KB5-18-hour product 


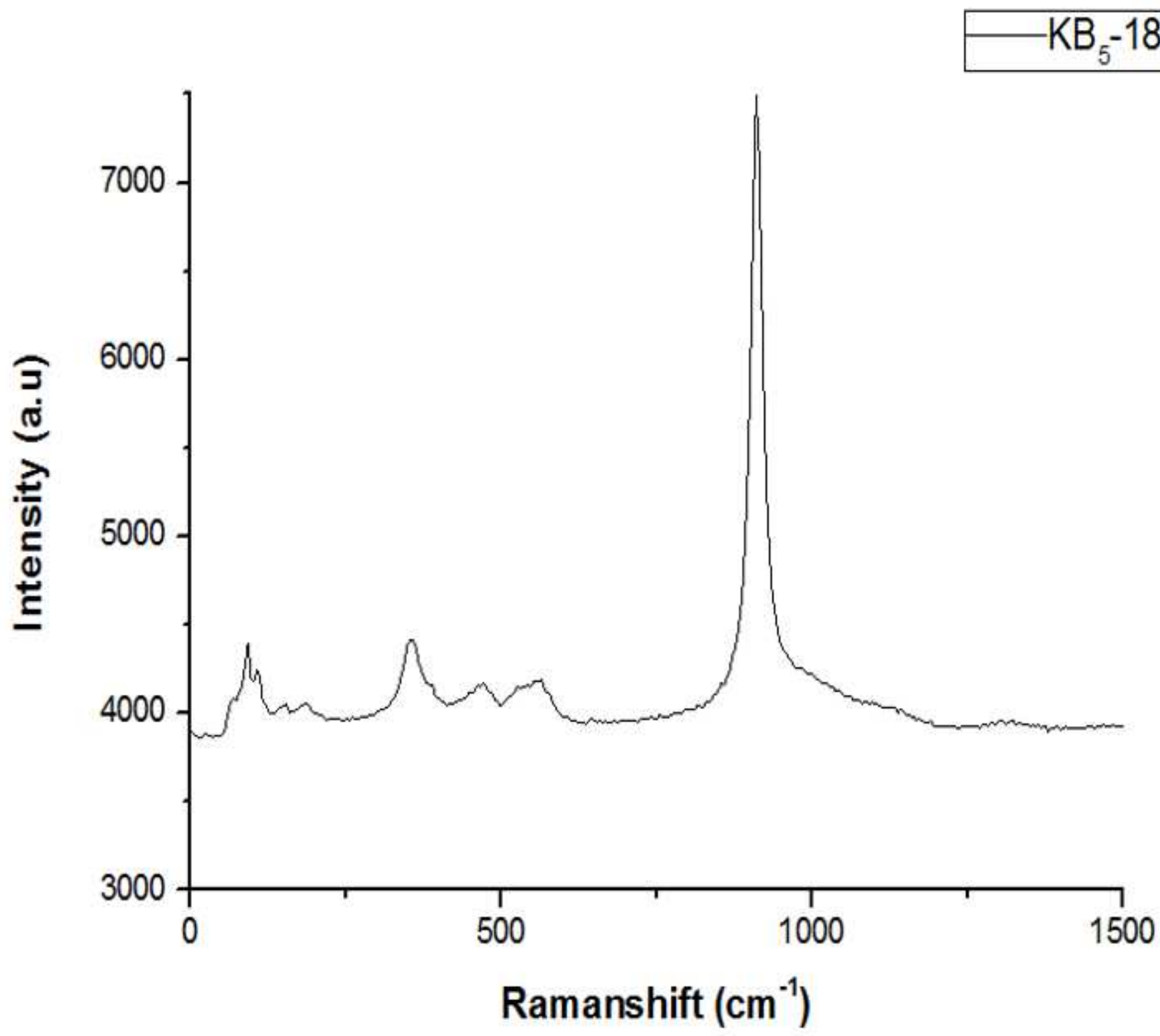

Figure 7

Raman spectrum of KB5-18 hour 